\title{
The Impact of IPO on the Secondary Stock Market-An Empirical Research
}

\author{
Xiaole Li, Xuhui Shi \\ Jinan University, School of Economics, Guangzhou, China \\ Email: lixiaole1107@126.com,tshxuhui@jnu.edu.cn
}

Received 4 March 2016; accepted 20 March 2016; published 23 March 2016

Copyright (C) 2016 by authors and Scientific Research Publishing Inc.

This work is licensed under the Creative Commons Attribution International License (CC BY). http://creativecommons.org/licenses/by/4.0/

c) (i) Open Access

\begin{abstract}
The IPO market can achieve financing function of the stock market after the IPO listed companies enter the securities market circulation. The IPO market and the secondary stock market complement each other and there is a strong relationship between them. In the study of the impact of the secondary stock market for the IPO market, based on supply and demand theory, the stock market expansion is a bad news which will lead to huge financing unilateral fall. This article mainly studies the impact of IPO on the secondary stock market. On the basis of theoretical analysis, we use linear regression model based on least-square method to explore the relationship between them, and confirm that the IPO issues have negative impact on the stock market retunes. When the external factors in the model and controlling factor within the model maintain equilibrium, the changes of the stock market rate of return caused by IPO financing are very significant. Stock market returns of IPO financing have considerable flexibility. At the end of the paper, some suggestions are put forward to strengthen the construction of the issuer integrity, the exit mechanism of listed companies and strengthen the supervision of matter and afterwards.
\end{abstract}

\section{Keywords}

IPOs, The Secondary Stock Market, Linear Regression

\section{Introduction}

Initial Public Offering refers to a company limited by shares to the public for the first time. As the main form of enterprises of direct financing, the IPO is an important link in the stock market. The IPO not only decides the price of the listed stock, the type and quantity, but also is the key to the stock market healthy operation. China officially started the stock market from the early 1990s when the Shanghai and Shenzhen stock exchanges had been established, and China's stock issuance system had also been established at the same time. China's stock issuing system after more than 20 years of evolution and reform overall went through a transformation process 
from the examination and approval system to the authorization system. This process also separately or in parallel has "quota management", "index management", "channel system" and "sponsor system"-four stages, in which quota management and index management belong to the examination and approval system; channel system and sponsor system belong to the authorization system.

Although China's stock issuing system since its establishment has been constantly changed according to the market situation, there is no denying to the fact that our country's stock market still has defects compared to the developed countries. As a result of the government's control and authorization of stock issue market insufficiency, it made China's stock market not guarantee the interests of investors in the secondary market. IPO authorization system was criticized by everyone for three reasons: first, the formation of artificial "quake lake" in the market channel; second it is easy to form the corruption of power; the third is to open up the door to corporate fraud. IPO authorization system which has become the target of public criticism is the product of superstition prior administrative approval and supervision of the work of thinking. Obviously, such a system and market rules are difficult to be a fusion. The development of capital market from the United States and other developed countries told us that it was inevitable that the authorization system came to an end.

The United States is a mature reference sample for the reform of registration system. Government department is the first barrier in American registration system, mainly performed by the Securities and Exchange Commission. The formal examination of Securities and Exchange Commission was open and transparent through the entire electronic information platform EDGAR system. Typically, the Securities and Exchange Commission will provide feedback within 30 days and then the issuer will make multiple feedback and response after an enterprise to be listed submitting registration documents. It usually needs 3 - 5 months when the registration documents submitted to the registration become effective. After the approval form, the Securities and Exchange Commission will announce the entry into force of the registration file, and the issuer may apply to a national stock exchange listing. Listing is free to choose between the issuer and the stock exchange. The Exchanges audit the scale, profitability and other aspects based on their listing requirements, to decide whether to allow the listing.

From the experience of mature Western markets, the registration system also has strict regulatory substance content. In order to achieve the purpose of regulation of market expansion rhythm, registration system usually combines with queuing system. Only when the market is relatively mature, the scale reaches a certain depth, the case of the issue size is relatively small impact on the operation of the market, and then the regulatory authorities will modify the queuing system to the practice of self-registered. Before the United States introduced cupboard shelf registration system in 1982, the registration system had implemented for nearly half a century. The regulatory authorities also have full control authority on the issue of rhythm so its IPO speed is not fast. Therefore, you cannot equate registration system with regulators not to carry on the examination as to substance. The substantive examination has difference between channels and means for examination. Registration system does not mean that regulators be fully liberalized on the IPO rhythm control. In other words, China Securities Regulatory Commission can give up right to examine and approve, but should have line up right. It was also real right not imaginary.

Stock issue market is the foundation of the stock in the secondary market. The bubble which exists in the new issues is bound to affect the healthy operation of the secondary market. IPO short-term premium and weak for a long time exist in the Chinese stock market. In order to prevent the sharp drops in the short term of stock market, China Securities Regulatory Commission tend to introduce Good policy or suspend the IPO. Pause and restart the IPO, becoming one of the most common means of regulating the stock market by regulatory authorities, which is the main reason why China's stock market is considered a "policy market". Generally, it is believed that IPO pause could restrict the market trend, and restart the IPO market may cool overheated market. Throughout the 20 years of development of China's stock market, China Securities Regulatory Commission implemented a total of nine IPO pause and restart.

IPO primary market and secondary market trading have a relationship of interdependence. The issuances of new shares in IPO market affect the market supply and demand of funds, and then have some impact on the secondary market. From historical point of view statistical results, the influence of the IPO single factors to the secondary market is relatively limited. They did not change the overall trend of the broader market, but often become the accelerator to make the secondary market up or down. The fact is that a short pause IPO makes a correction in most cases, but the long-term downward trend has not suspended because the IPO. It cannot completely reverse the bearish market and restart IPO will have a negative impact on the secondary market. 
The release of Registration System has no doubt. But at the same time, according to the actual situation of China's stock market, the concrete implementation of IPO registration system cannot copy other countries' experience. The study of direction and degree of the influence of the IPO of stocks in the secondary market is necessary for the establishment and perfection of China's stock market after registration system released.

\section{Literature Review}

Abundant evidence shows that China's securities market is a weak efficient market. IPO issuing system has disadvantages as well as investors keen to chase a new shares make the secondary market intense distortion. In this case, the domestic scholars have generally agreed that IPO has a negative effect on stock market. When study the effect of IPO of stocks in the secondary market, we will generalize the IPO literature, to pave the way for the theoretical analysis and empirical study later.

Baker and Wurgler [1] studied the overall yield during the issuance of new shares on the American stock market from 1929 to 1997 . They found that the market usually fell in a bear market when concentrated market shares issued and rebound when slow the IPO rhythm. The two scholars believe that the inefficiency of the US market is the cause of this phenomenon.

Ofek and Richardson [2] argue that the stock supply was increased after the IPO lockup and as a whole it would be unfavorable for the new shares and the price of the stock market.

Braun and Larrain [3] demonstrated that in emerging markets IPO will have the same negative impact on the stock market. They examined 22 different level of development of countries and made regression analysis of the country's market index, IPO financing and transaction amount. It is concluded that the smaller openness of the country, the greater negative impact on the stock market.

Baoguo $\mathrm{Hu}$ and Tong Zeng [4] found the negative correlation between the indexes and the stock market expansion from 1994 to 1997 new listings data. They thought the stock market expansion is the only way for the development of Chinese stock market. But it still needs guidance of government intervention if the stock market was not mature. Government controlling over the pace of expansion and the stock market has become the important factors that affect secondary market.

$\mathrm{Min} \mathrm{Wu}$ [5] did the least squares regression on the market index and the amount of new shares issued, which used the China's A-share and B-share markets data from 1999 to 2001. They found that the amount of new shares issued within 8 weeks was significantly affected by the presence on the market index, while the market activity measured by the volume was irrelevant with the amount of new shares issued.

Zhenbin Tang [6] analyzed the influence of both positive and negative effect on the IPO market index, which included a positive impact that IPO approval system improved the quality of IPO and rising performance of listed companies could promote the upgrade of market index. While new issues brought new investment opportunities and a lot of money for shares in hot pursuit can active stock market in a short time. Negative impacts include: IPO reduced the secondary market stock funds and resulted in an imbalance of supply and demand of market funds; expansion rumors brought investors psychological pressure; super large cap occupied more internal funds and brought bigger speculative bubble.

Baisan Xie and Wenying Shen [7] suggested that the expansion behavior of Chinese stock market reducing the wealth effect of shareholders and low dividend made the investors turned to other collective investment vehicles. In addition, the equity financing in this way by some companies as the most direct means of money. The listed companies relied too much on equity financing which had violated the modern capital structure theory and focused on the capital position rather than Industrial development expense, eventually leading to the company's profit decline and reflected in the stock price and resulting in the majority of investors suffered losses.

Dongmin Kong and Kehua Fu [8] studied the 82 listed companies from 1998 to 2003. They used event study to examine the response of the company issuing the stock market behavior, and ultimately resulted market reactions to secondary offerings are negative. The negative impact was small when the market rose and the negative impact was large when the market decline.

Yucheng Zhao [9] selected the China A-share market data from 2006 to 2010 and proved that the impact of the freezing of funds on the market index sequence fluctuation more significant than funds of new listings, which based on GC-MSV model Granger causality test. But he did not specify the direction of impact.

Dehong Liu, Min Dang and Tao Li [10] verified the IPO financing amount of correlation with the Shanghai securities composite index rate of return from 2006 to 2009 by the VAR model. They concluded that this 
month's IPO would be 9 months of negative effects on the Shanghai securities composite index, and it was most severe in the second months. On the other hand, the Shanghai securities composite index rate of return on the stock market also affected the amount of financing. The reasons were that the listed companies generally tended to issue shares when the market offering a higher price, and the irrational behavior of investors would also motivate the wholesale funding of the company.

Limin Wang, Feng Gao and Yajia Xue [11] used the granger causality test analysis the point of announcement date, the purchase date, the funds thaw data and the launch date of IPO from 2007 to 2011 . They concluded that the influence of the IPO along with the market trends, when the market was bullish then IPO had negative impact on stock market the stock market rate of return and the impact of the announcement date was greatest. When the market was in decline, different points had positive or negative influence on the stock market.

Jianglin Lv and Peng Zeng [12] obtained there was excessive expansion of the stock market in the period 1990 to 2010 using VEC model, which made the current share price index should be significantly lower than the theoretical level. They suggested that appropriately reduce the supply of stock and reduce the size of IPO financing of China's stock market is an effective way out of the doldrums.

\section{Methodology}

\subsection{Empirical Framework}

The empirical framework is the multiple linear regression models. The multiple linear regression models can be written as Equation (1):

$$
y_{t}=\beta_{0}+\beta_{1} x_{t 1}+\beta_{2} x_{t 2}+\cdots+\beta_{t} x_{t k}+\mu_{t}
$$

When given a sample as $\left(y_{t}, x_{t 1}, x_{t 2}, \cdots, x_{t k}\right), t=1,2, \cdots, T$, the multiple linear regression model can be written as Equation (2):

$$
\left\{\begin{array}{l}
y_{1}=\beta_{0}+\beta_{1} x_{11}+\beta_{2} x_{12}+\cdots+\beta_{t} x_{1 k}+\mu_{1} \\
y_{2}=\beta_{0}+\beta_{1} x_{21}+\beta_{2} x_{22}+\cdots+\beta_{t} x_{2 k}+\mu_{2} \\
\cdots \\
y_{T}=\beta_{0}+\beta_{1} x_{T 1}+\beta_{2} x_{T 2}+\cdots+\beta_{t} x_{T k}+\mu_{T}
\end{array}\right.
$$

To ensure to get the optimal estimator, the regression model should meet the following assumptions.

The principle of least squares estimation is the minimum sum of squared residuals.

The assumption one: $E(\mu)=0$;

The assumption two: $\operatorname{Var}(\mu)=E\left(\hat{\mu} \hat{\mu}^{\prime}\right)=\sigma^{2} I$;

The assumption three: $E\left(X^{\prime} \mu\right)=0$;

The assumption four: $r K\left(X^{\prime} X\right)=r K(X)=k+1$;

The assumption five: Explanatory variables are random, and when $T \rightarrow \infty, T^{-1} X^{\prime} X \rightarrow Q$, in which $Q$ is a non-degenerate matrix of finite value.

The principle of least squares is minimizing the sum of squared residuals. It can be written as Equation (3):

$$
\begin{aligned}
\min S & =(Y-X \hat{\beta})^{\prime}(Y-X \hat{\beta}) \\
& =Y^{\prime} Y-\hat{\beta}^{\prime} X^{\prime} Y-Y^{\prime} X \hat{\beta}+\hat{\beta}^{\prime} X^{\prime} X \hat{\beta} \\
& =Y^{\prime} Y-2 \hat{\beta}^{\prime} X^{\prime} Y+\hat{\beta}^{\prime} X^{\prime} X \hat{\beta}
\end{aligned}
$$

Because the $Y^{\prime} X \hat{\beta}$ is a scalar, then $\frac{\partial S}{\partial \hat{\beta}}=-2 X^{\prime} Y+2 X^{\prime} X \hat{\beta}=0$. So we have obtained Equation (4):

$$
\hat{\beta}=\left(X^{\prime} X\right)^{-1} X^{\prime} Y
$$

The estimate of the regression model can be written as Equation (5): 


$$
Y=X \hat{\beta}+\hat{\mu}=\hat{Y}+\hat{\mu}
$$

The core variable of this article is the size of the IPO financing. We realized that the influence of scale factor on the impact factor may show some degree of economical scale or uneconomical scale. The IPO financing scale on the fluctuation of the stock market also needs to consider the problem of economical scale and we will take the economical scale into consideration in the model. The value of Stock market varies due to different period. So we must consider the influence of the market value.

The dependent variable of this article is the stock index returns which used the weekly closing prices of CSI 500 index to calculate. The explanatory variable is the amount of total funds rose which is all the IPO financing amount in a week. Due to fluctuations in the stock market price is influenced by a number of objective and subjective factors. These factors include the health of the real economy, monetary policy, the stock market features, investor sentiment and expectations, and uncertainty impact, etc.

In order to study the impact on IPO stock market volatility more precisely, this article will introduce the relevant variables in the model as characteristic variables to control the above objective and subjective factors. Model variable indicators have been provided as Table 1.

For both qualitative and quantitative analysis, this paper uses the LS model and the structure of the model equation is as Equation (6):

$$
\begin{aligned}
z y_{t}= & \alpha_{1}+\alpha_{2} \cdot \operatorname{dum}_{t}+\beta_{1} \cdot t f r_{t+1}+\beta_{2} \cdot \operatorname{dum}_{t} \cdot t f r_{t+1} \\
& +\gamma_{1} \cdot l m b i_{t}+\gamma_{2} \cdot n c s_{t}+\gamma_{3} \cdot \text { feri }_{t}+\gamma_{4} \cdot m t o_{t}+\varepsilon_{t}
\end{aligned}
$$

\subsection{Data and Methods}

This paper selects data from June 2006 to June 2015, and uses the weekly time series data. The stock market and IPO date get from the Shanghai stock exchange and the Shenzhen stock exchange website. Monetary policy data obtain from the People's Bank of China and the China State Administration of Foreign Exchange website. The real economy data obtain from the Chinese National Bureau of Statistics data site. Summary of the deterministic statistics of the explanatory variable considered has been provided as Table 2.

\section{Results and Discussion}

\subsection{Descriptive Analysis}

\begin{tabular}{|c|c|c|}
\hline Variable & Variable declaration & Variable identifier \\
\hline \multicolumn{3}{|l|}{ Dependent variable } \\
\hline The stock index returns & The weekly closing prices of CSI 500 index to calculate & ZY \\
\hline \multicolumn{3}{|l|}{ Explanatory variable } \\
\hline Total funds raised & $\begin{array}{l}\text { The ratio of weekly the IPO financing amount to the negotiable } \\
\text { market cap }\end{array}$ & TFR \\
\hline \multicolumn{3}{|l|}{ Control variable } \\
\hline Leading macro-economic boomimg index & $\begin{array}{l}\text { The weekly growth rate of leading macro-economic boomimg } \\
\text { index }\end{array}$ & LMBI \\
\hline Net currency supply & $\begin{array}{l}\text { The growth rate of the people's bank of China net currency supply } \\
\text { peer week }\end{array}$ & NCS \\
\hline Foreign exchange reserves increment & $\begin{array}{l}\text { The growth rate of the foreign exchange reserves increment peer } \\
\text { week }\end{array}$ & FERI \\
\hline Market turnover & The market turnover of the stock market peer week & MTO \\
\hline \multicolumn{3}{|l|}{ Dummy Variable } \\
\hline CSI 500 index yield sign & when the $Z Y>0$ the DUM equal 1 , other than the DUM equal 0 & DUM \\
\hline
\end{tabular}

According to the data collected, IPO financing on the secondary stock market can be seen from Figure 1.

Table 1. Model variable indicators. 


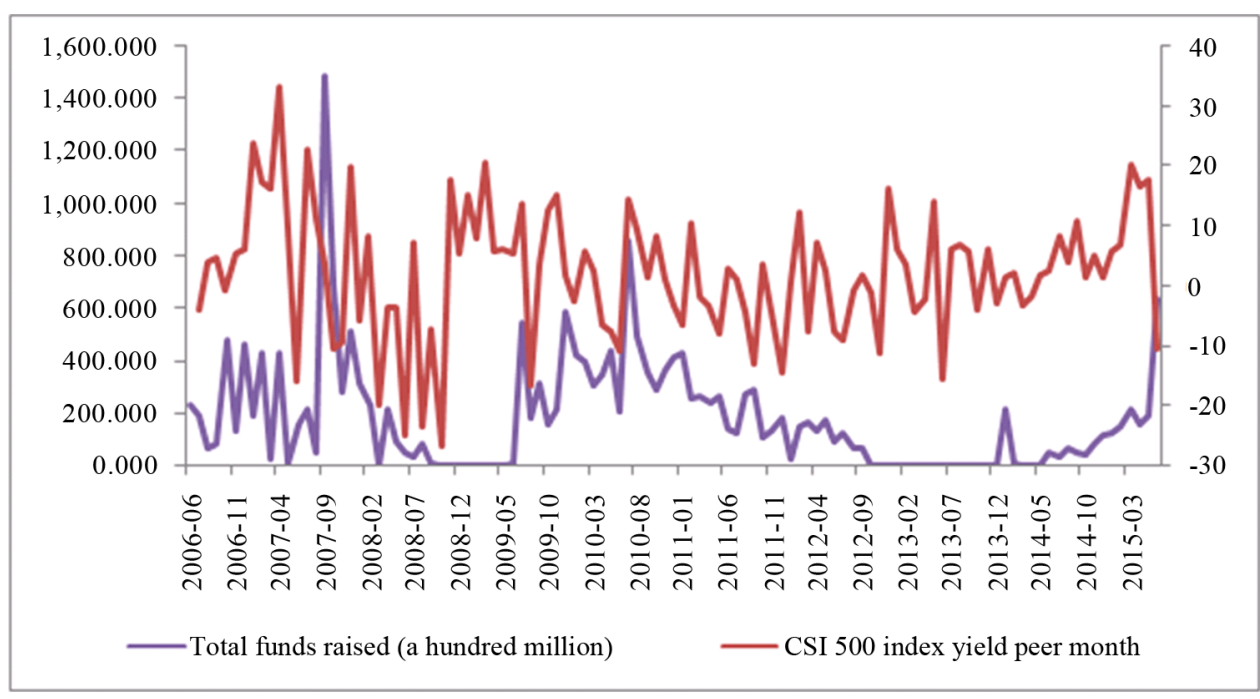

Figure 1. June 2006-June 2015: The trend of Total funds raised and CSI 500 index.

Table 2. Summary of the deterministic statistics of the explanatory variable considered.

\begin{tabular}{|c|c|c|c|c|c|c|c|c|c|}
\hline Variable & Mean & Median & Maximum & Minimum & Std. Dev & Skewness & Kurtosis & Jarque-Bera & Probability \\
\hline $\begin{array}{l}\text { The stock index returns } \\
\text { (ZY) }\end{array}$ & 0.386712 & 1.023046 & 17.91244 & -24.0469 & 4.920436 & -0.74371 & 6.14065 & 230.9555 & 0 \\
\hline Total funds raised (TFR) & 0.054766 & 0.010361 & 2.682621 & 0 & 0.19263 & 8.149821 & 89.97308 & 149748.6 & 0 \\
\hline $\begin{array}{l}\text { Leading macro-economic } \\
\text { boomimg index (LMBI) }\end{array}$ & -0.00658 & -0.00317 & 0.442358 & -0.78879 & 0.128217 & -0.34956 & 6.28949 & 216.2943 & 0 \\
\hline Net currency supply (NCS) & 7.12945 & 0.488586 & 3887.556 & -819.919 & 213.7012 & 12.95705 & 239.8827 & 1086012 & 0 \\
\hline $\begin{array}{l}\text { Foreign exchange reserves } \\
\text { increment (FERI) }\end{array}$ & 3.693601 & -1.86966 & 1574.802 & -883.771 & 150.4649 & 2.498641 & 39.07899 & 25372.49 & 0 \\
\hline Market turnover (MTO) & 13.28774 & 11.56703 & 51.48355 & 1.945008 & 6.995048 & 1.472007 & 5.922506 & 329.1081 & 0 \\
\hline $\begin{array}{l}\text { CSI } 500 \text { index yield sign } \\
\text { (DUM) }\end{array}$ & 0.538126 & 1 & 1 & 0 & 0.499088 & -0.15295 & 1.023394 & 76.51047 & 0 \\
\hline
\end{tabular}

This paper uses the Augmented Dickey-Fuller Unit Root Test to test the stationary of the variables. Variables stationary test- Augmented Dickey-Fuller Unit Root Test provided as Table 3.

Test results indicate all the explanatory variables and the explanatory variables involved in the model are highly stable, which means that the result of the regression model is not a fallacy regression model with stability and continuity.

\subsection{Estimated Results}

We use the least squares estimate to get the parameter estimates.

The estimated results provided as Table 4.

The analysis found that most of the regression coefficients of the estimated model are highly significant. $R^{2}$ reaches $46 \%$, Durbin-Watson stat reaches 1.96 . Model is significant. The coefficient of $t f f_{t+1}$ is significantly negative, which is consistent with theoretical expectations.

\section{Conclusions and Recommendations}

This paper confirmed that the IPO issues have negative impact on the stock market retunes by empirical linear regression model. When the external factors in the model and controlling factor within the model maintain equilibrium, the changes of the stock market rate of return caused by IPO financing are very significant. Stock market returns of IPO financing have considerable flexibility. 
Table 3. Variables stationary test-augmented Dickey-Fuller unit root test.

\begin{tabular}{ccccccc}
\hline Variable & ADF & $1 \%$ Level & $5 \%$ Level & $10 \%$ Level & Prob. & Stationary \\
\hline The stock index returns (ZY) & -18.54282 & -2.570021 & -1.941516 & -1.616235 & 0.0000 & stationary \\
Total funds raised (TFR) & -5.090882 & -2.570204 & -1.941542 & -1.616218 & 0.0000 & stationary \\
Leading macro-economic boomimg index (LMBI) & -5.357458 & -2.570066 & -1.941522 & -1.616231 & 0.0000 & stationary \\
Net currency supply (NCS) & -4.424414 & -2.570066 & -1.941522 & -1.616231 & 0.0000 & stationary \\
Foreign exchange reserves increment (FERI) & -5.897008 & -2.570021 & -1.941516 & -1.616235 & 0.0000 & stationary \\
Market turnover (MTO) & -4.387741 & -3.444436 & -2.867645 & -2.570085 & 0.0004 & stationary \\
CSI 500 index yield sign (DUM) & -19.31714 & -3.444404 & -2.867631 & -2.570077 & 0.0000 & stationary \\
\hline
\end{tabular}

Table 4. Estimated results.

\begin{tabular}{cccccc}
\hline Variable & Coefficient signs & Coefficient & Std. Error & t-stat. $\beta /$ Std. Error & $\mathrm{P}>|z|$ \\
\hline$c$ & $\alpha_{1}$ & -3.854109 & 0.392548 & -9.818178 & 0.0000 \\
$\operatorname{dum}_{t}$ & $\alpha_{2}$ & 5.894813 & 0.354483 & 16.62933 & 0.0000 \\
$t f f_{t+1}$ & $\beta_{1}$ & -3.242470 & 2.329851 & -1.391707 & 0.0847 \\
$\operatorname{dum}_{t} t f f_{t+1}$ & $\beta_{2}$ & 4.297112 & 2.508117 & 1.713282 & 0.0873 \\
$l m b i_{t}$ & $\gamma_{1}$ & 1.670125 & 1.323402 & 1.261994 & 0.2076 \\
$n c s_{t}$ & $\gamma_{2}$ & 0.000611 & 0.000777 & 0.786642 & 0.2319 \\
$f e r i_{t}$ & $\gamma_{3}$ & -0.001765 & 0.001109 & -1.591693 & 0.1122 \\
$m t o_{t}$ & $\gamma_{4}$ & 0.086450 & 0.025612 & 3.375411 & 0.0008 \\
\hline
\end{tabular}

Some suggestions are put forward to strengthen the construction of the issuer integrity, the exit mechanism of listed companies and strengthen the supervision of matter and afterwards.

First, strengthen the construction of the issuer integrity. The issuer is the first responsible person for information disclosure and must ensure the authenticity, accuracy and completeness of the information disclosed. The issuer shall unconditionally bear legal responsibility for information disclosure content existing false records, misleading statements or major omissions.

Second, China Securities Regulatory Commission must establish a complete stock market exit mechanism and adhere to the principle of survival of the fittest listed companies.

Finally, registration assessment should vigorously strengthen the exit mechanism of listed companies and strengthen the supervision of matter and afterwards. It not only cannot be replaced, but should be more strengthened. The duty of the regulatory authority is the supervision and control, and safeguarding investors' legitimate rights and interests.

\section{References}

[1] Macolm, B. and Wurgler, J. (2009) The Equity Share in New Issues and Aggregate Stock Returns. Journal of Finance, 55, 2219-2237.

[2] Eli, O. and Richardson, M. (2000) The IPO Lock-Up Period Implications for Market Efficiency and Downward Curves. Working Paper.

[3] Braun, M. and Larrain, B. (2009) Do IPOs Affect the Prices of Other Stocks? Evidence from Emerging Markets. The Review of Financial Studies, 22, 323-361. http://dx.doi.org/10.1093/rfs/hhn025

[4] Hu, B.G. and Zeng, T. (1997) The Statistical Analysis of the Stock Market Expansion. Statistics and Decision, 9, 2021.

[5] Wu, M. (2003) The Correlation between IPO Volume and Stock Index. Shanghai Finance and Taxation, 12, 26-27.

[6] Tang, Z.B. (2003) An Empirical Analysis of Our Country Stock Market Expansion and Market Trends. Journal of Central University of Finance and Economics, 5, 20-25. 
[7] Xie, B.S., Shen, W.Y. (2004) Risk and Countermeasures of Chinese Stock Market Over-Expansion Analysis. Price Theory and Practice, 8, 40-41.

[8] Kong, D.M. and Fu, K.H. (2005) The Reaction and Impact of China's Stock Market Seasoned Equity Offing. World Economy, 10, 51-57.

[9] Zhao, Y.C. (2012) An Analysis of the Impact of IPO on the Secondary Market. Studies of Financial and Economic Issues, 2, 58-62.

[10] Liu, H., Dang, M. and Li, T. (2010) An Empirical Analysis of shanghai A-Share Market Index and IPO Financing. Journal of Beijing Transportation University, 3, 78-83.

[11] Wang, L.M., Gao, F. and Xue, Y.J. (2012) An Empirical Analysis of the IPO Impact on Stock Market Returns. The 7th China Management Symposium, 8, 1-7.

[12] Lv, J.L. and Zeng, P. (2012) Moderate Scale of Financing in China's Stock Market Research. Finance Forum, 6, 7278. 